Jurnal

Kardiologi Indonesia

J Kardiol Indones. 2013;34:66-8

ISSN 0126/3773

\title{
Only Single Pacing On Dual Chamber Pacemaker
}

\author{
Yoga Yuniadi
}

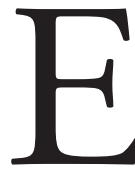

KG merupakan pemeriksaan penunjang yang sangat penting untuk evaluasi pasien pemakai alat pacu jantung menetap. Melalui EKG fungsi pemacuan dan fungsi sensing alat pacu jantung menetap dapat ditentukan dengan cukup akurat. Dengan mengantongi informasi jenis alat pacu jantung menetap yang digunakan, EKG bagi seorang kardiolog akan memberikan informasi adanya fenomena undersensing, oversensing, loss of capture, loss of output, dan sebagainya.

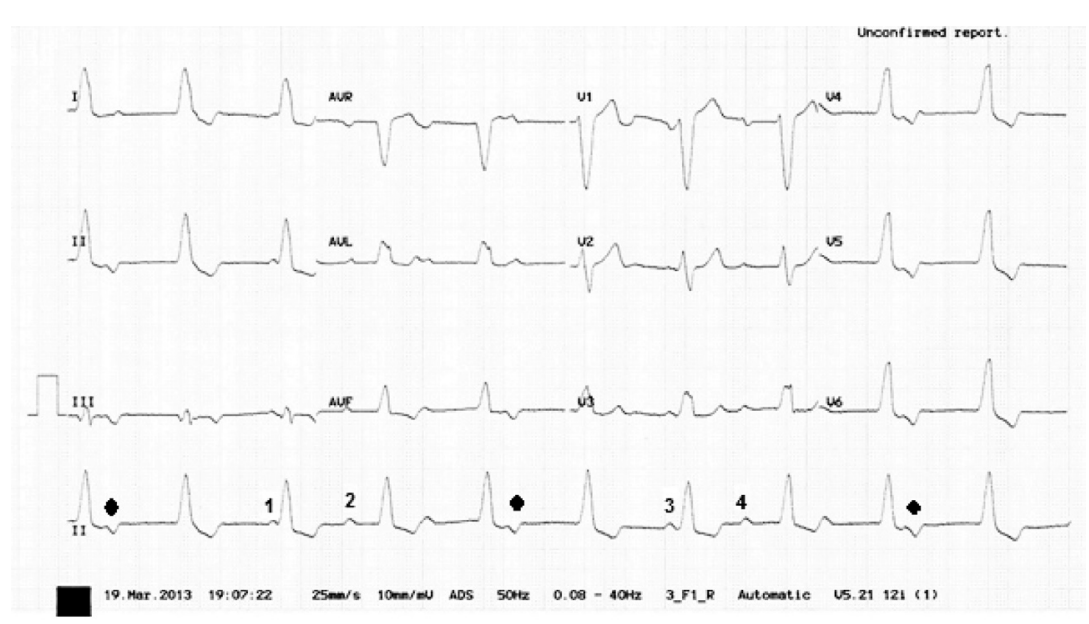

Gambar 1. EKG 12 sadapan. Tampak irama pemacuan di ventrikel kanan dengan morfologi LBBB dengan laju $60 \mathrm{kpm}$. Terlihat beberapa gelombang $\mathrm{P}$ yang bebas tanpa diikuti oleh spike pemacuan ventrikel sebagaimana yang diharapkan pada suatu alat pacu jantung kamar ganda. Angka 1, 2, 3 dan 4 menunjukkan gelombang P yang terlihat jelas, sedangkan tanda ketupat padat menunjukkan gelombang $\mathrm{P}$ yang terkubur dalam gelombang $\mathrm{T}$ sehingga mengubah morfologi gelombang $\mathrm{T}$.

\section{Alamat korespondensi:}

Dr. dr. Yoga Yuniadi, SpJP, Divisi Aritmia, Departemen Kardiologi dan Kedokteran Vaskuler FKUI dan Pusat Jantung Nasional Harapan, Kita, JI S Parman Kav 87 Jakarta I I 420, E-mail: yogayun@yahoo.com

\section{Kasus}

Seorang pria warga negara India, 52 tahundatang ke klinik rawat jalan untuk pengecekan alat pacu jantung. Alat pacu jantung menetap kamar ganda (dual chambers) dipasang satu tahun yang lalu di India 
atas indikasi blok AV total. Ini adalah kunjungan pertama kalinya di klinik aritmia di Indonesia. Tidak ada keluhan sama sekali, pasien merasa jauh lebih baik setelah pemasangan alat pacu jantung menetap. Pemeriksaan fisik tidak didapatkan kelainan kecuali adanya obesitas. Rekaman EKG 12 sadapan di klinik diperlihatkan pada gambar 1 .

Apa yang terjadi dengan alat pacu jantung menetap pasien ini? Apakah alat pacu jantung berfungsi dengan baik? bila pengaturan sensitivitas gelombang $\mathrm{P}$ terlalu rendah sehingga gelombang $\mathrm{P}$ intrinsik tidak berhasil dilihat (sensed) oleh alat pacu jantung melalui lead atrium. Akan tetapi bila terjadi undersensing seharusnya terlihat spike pemacuan di atrium yang dikuti oleh gelombang $P$ pada laju pemacuan yang telah diprogram dan hal ini tidak terjadi. Maka timbul kecurigaan terjadi loss of output pemacuan atrium, yaitu gagalnya energi listrik yang dikeluarkan oleh alat pacu jantung menetap tiba di atrium melalui lead atrium. Loss of output biasanya

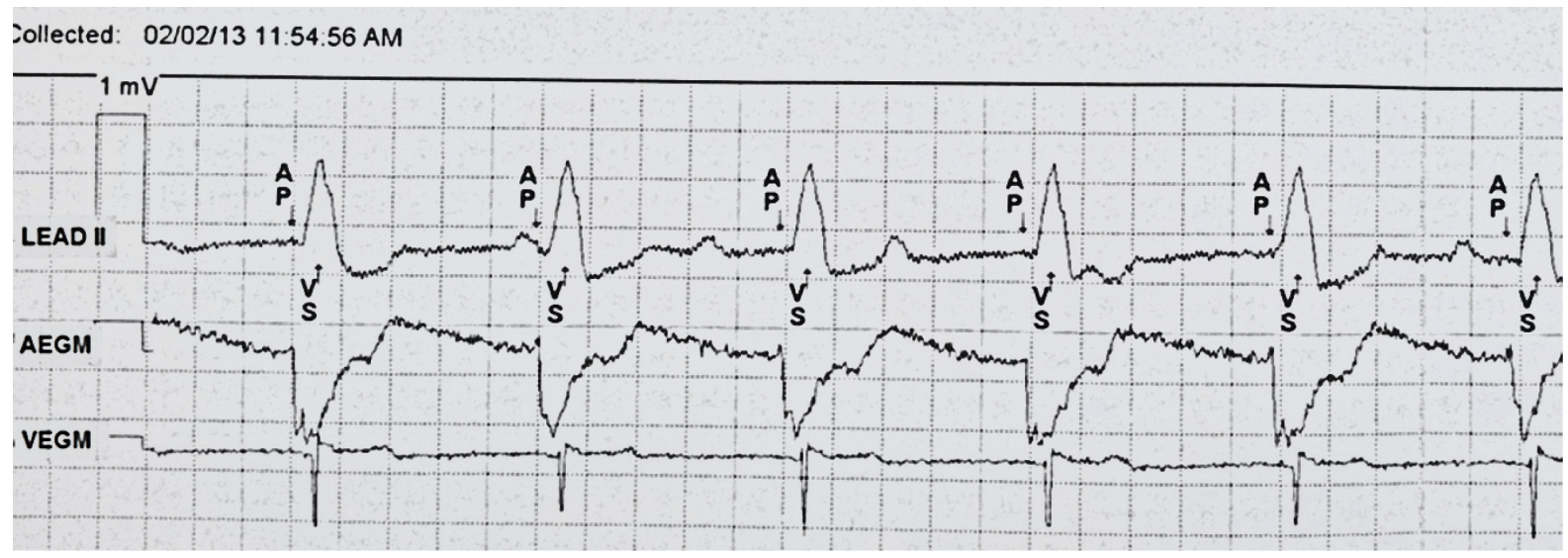

Gambar 2.Gambar EKG permukaan sadapan II, elektrogram atrium (AEGM) dan elektrogram ventrikel (VEGM).

\section{Pembahasan}

Pada gambar 1 cukup mudah untuk melihat adanya disosiasi A-V yaitu adanya gelombang $\mathrm{P}$ yang regular dengan laju $80 \mathrm{kpm}$, sementara laju pemacuan ventrikel juga teratur dengan laju $60 \mathrm{kpm}$. Ini mudah dibuktikan dengan memperhatikan gelombang $\mathrm{P}$ (1, 2, 3 dan 4) yang memiliki interval PR yang berbedabeda. Tidak terlihat hubungan antara gelombang $\mathrm{P}$ dan pemacuan ventrikel yang sebetulnya diharapkan terjadi pada pemacuan kamar ganda. Bukan saja tidak terlihat A-V sinkroni tetapi spike pemacuan ventrikel yang seharusnya mengikuti gelombang $\mathrm{P}$, pada jarak $A V$ delay yang terprogram, juga tidak terlihat (perhatikan gelombang P no 2 dan 4). Pada pasien dengan blok AV total, spike ventrikel diharapkan terjadi pada jarak 120- 150 mdet setelah gelombang P. Mengapa hal ini terjadi? Bagaimana mekanismenya?

Boleh jadi kita berfikir bahwa alat pacu jantung menetap gagal melihat gelombang $\mathrm{P}$ intrinsik yang dikenal dengan istilah undersensing. Undersensing terjadi terjadi akibat kerusakan lead.Kegagalan fungsi pacu dan fungsi sensing lead atrium menyebabkan lead ventrikel tetap berfungsi memberikan pemacuan pada laju pemacuan yang terprogram.

Masih adakah kemungkinan lain?Ya, kemungkinan lain adalah dislodge atau berpindah tempatnya lead atrium ke ventrikel. Hal ini akan menimbulkan pemacuan ventrikel oleh lead atrium dan inhibisi pemacuan oleh lead ventrikel karena lead ventrikel melihat (sensed) aktivitas listrik di ventrikel yang disebabkan oleh lead atrium. Sejauh inihanya dengan melihat EKGtelah sangat membantu menentukan adanya malfungsi alat pacu jantung menetap dengan beberapa kemungkinan mekanismenya. Dengan demikian seorang kardiologis sudah dapat mendiagnosis dan menentukan rujukan sesuai dengan beratnya masalah.

Untuk memastikan masalah sesungguhnya pada alat pacu jantung menetap pasien ini maka diperlukan interogate alat pacu jantung memakai alat programmer. Interogasi alat pacu jantung menetap memakai 
alat programmer menampilkan gambaran EKG dan elektrogram seperti terlihat pada gambar 2.

Gambar 2 sangat menarik. Elektrogram atrium yang menunjukkan pemacuan di atrium (ditandai dengan AP pada sadapan II) selalu bersamaan dengan awitan kompleks QRS, elektrogram ventrikel hanya menunjukkan aktivitas sensing (ditandai dengan VS pada sadapan II). Jarak AP ke VS kurang lebih 120 mdet. Sementara itu setiap terjadi gelombang P sama sekali tidak dilihat (sensed) oleh elektrogram atrium dan bukan juga hasil dari pemacuan atrium. Gambar 2 telah memberikan jawaban terhadap dugaan mekanisme gambaran EKG ang diperlihatkan oleh gambar 1, yaitu bukan loss of output atrium yang terjadi melainkan lead atrium mengalami dislodge ke ventrikel sehingga memberikan pemacuan di ventrikel, dengan demikian lead ventrikel yang diatur pada jarak AV delay 120 mdet hanya melakukan sensed depolarisasi ventrikel yang dihasilkan oleh pemacuan lead atrium.

Sebetulnya, selain terjadi dislodge lead atrium ke ventrikel keadaan di atas dapat juga terjadi karena lead atrium dan ventrikel tertukar yaitu lead atrium dihubungkan dengan header ventrikel dan sebaliknya. Untuk membuktikannya diperlukan foto toraks untuk melihat lokasi lead atrium. Foto thoraks (tidak dilampirkan) memerlihatkan letak lead atrium yang mengalami dislodge ke basal ventrikel kanan. Dengan demikian terjawab sudah permasalahan pasien ini yaitu terjadi dislodgelead atrium ke ventrikel kanan. Maka diperlukan reposisi lead atrium kembali ke apendiks atrium kanan agar didapatkan manfaat $\mathrm{AV}$ sinkroni dari alat pacu jantung kamar ganda.

Displacement/dislodge lead alat pacu jantung menetap didefinisikan sebagai perubahan posisi lead baik disertai atau tidak disertai malfungsi pemacuan. Dislodge hanya mempunyai kemaknaan klinis bila disertai malfungsi pemacuan. Dislodge dapat terjadi dini yaitu kurang dari 6 minggu pasca implantasi atau lambat. Displacement dini lebih sering terjadi pada lead atrium yaitu mencapai $3.8 \%$, sedangkan pada lead ventrikel hanya $1 \% .^{1-3}$

Umumnya malfungsi alat pacu jantung menetap akibat dislodge lead diketahui saat pemeriksaan EKG. Bila pasien sangat tergantung pada fungsi pemacuan alat pacu jantung maka tentu akan menimbulkan gejala yang jelas mulai dari keleyengan hingga sinkop berulang bahkan stroke. Pada pasien di atas tidak ada gejala karena yang mengalami dislodge adalah lead atrium yang jatuh ke ventrikel dan menimbulkan pemacuan di ventrikel. Walaupun pasien ini sangat tergantung pada alat pacu, tetapi lead atrium yang dislodge ke ventrikel tetap memberikan frekuensi pemacuan yang memadai.

Tatalaksana dislodge lead berbeda tergatung pada kejadianya dini atau lambat. Dislodge dini umumnya mudah direposisi, sedangkan dislodge lambat kadang kala memerlukan implantasi lead baru karena lead lama sudah mengalami fibrosis yang sulit dilepaskan.

\section{Daftar Pustaka}

1. Bardy GH, Hofer B, Johnson G, Kudenchuk PJ, Poole JE, Dolack GL, et al. Implantable transvenous cardioverterdefibrillators. Circulation 1993;87(4):1152-68.

2. Chauhan A, Grace AA, Newell SA, Stone DL, Shapiro LM, Schofield PM, et al. Early complications after dual chamber versus single chamber pacemaker implantation. Pacing Clin Electrophysiol 1994;17(11 Pt 2):2012-5.

3. Fuertes B, Toquero J, Arroyo-Espliguero R, Lozano IF. Pacemaker lead displacement: mechanisms and management. Indian Pacing Electrophysiol J 2003;3(4):231-8. 